\title{
High Altitude Venus Operational Concept (HAVOC): Proofs of Concept
}

\author{
Christopher A. Jones ${ }^{1}$ and Dr. Dale C. Arney ${ }^{2}$ \\ NASA Langley Research Center, Hampton, VA 23681 \\ George Z. Bassett ${ }^{3}$ \\ University of Texas, Austin, TX \\ James R. Clark ${ }^{4}$ \\ Massachusetts Institute of Technology, Cambridge, MA \\ Anthony I. Hennig 5 \\ Rochester Institute of Technology, Rochester, NY \\ Jessica C. Snyder 6 \\ Rowan University, Glassboro, NJ
}

\begin{abstract}
The atmosphere of Venus is an exciting destination for both further scientific study and future human exploration. A recent internal NASA study of a High Altitude Venus Operational Concept (HAVOC) led to the development of an evolutionary program for the exploration of Venus, with focus on the mission architecture and vehicle concept for a 30-day crewed mission into Venus's atmosphere at $50 \mathrm{~km}$. Key technical challenges for the mission include performing the aerocapture maneuvers at Venus and Earth, inserting and inflating the airship at Venus during the entry sequence, and protecting the solar panels and structure from the sulfuric acid in the atmosphere. Two proofs of concept were identified that would aid in addressing some of the key technical challenges. To mitigate the threat posed by the sulfuric acid ambient in the atmosphere of Venus, a material was needed that could protect the systems while being lightweight and not inhibiting the performance of the solar panels. The first proof of concept identified candidate materials and evaluated them, finding FEPteflon to maintain $90 \%$ transmittance to relevant spectra even after $\mathbf{3 0}$ days of immersion in concentrated sulfuric acid. The second proof of concept developed and verified a packaging algorithm for the airship envelope to inform the entry, descent, and inflation analysis.
\end{abstract}

\section{Introduction}

$\mathrm{H}$ UMAN observation of and interest in Venus reaches back into ancient history. The early astronomers of China, Babylon, Greece, and India saw Venus as a bright, early morning star that appeared shortly before sunrise and disappeared quickly after sunset. Later, Venus played a pivotal role in the Enlightenment, as astronomers of that era used the phases of Venus, caused by the planet's proximity to the Sun and brief periods of visibility, as evidence to disprove geocentric theories. Now, Venus serves as a place to test new technologies, explore extreme planetary chemistries, and understand and develop climate models of other worlds. Recent explorations during the late 20th Century pursued primarily by the Soviet Union found Venus to be a hellish wasteland. The surface pressure under the

\footnotetext{
${ }^{1}$ Aerospace Engineer, Space Mission Analysis Branch, MS 462, AIAA Member.

${ }^{2}$ Aerospace Engineer, Space Mission Analysis Branch, MS 462, AIAA Member.

${ }^{3}$ Student Engineer, Space Mission Analysis Branch, MS 462, AIAA Student Member.

${ }^{4}$ Student Engineer, Space Mission Analysis Branch, MS 462, AIAA Student Member.

${ }^{5}$ Student Engineer, Space Mission Analysis Branch, MS 462.

${ }^{6}$ Student Engineer, Space Mission Analysis Branch, MS 462, AIAA Student Member.
}

American Institute of Aeronautics and Astronautics 
massive atmosphere is 92 times that of Earth's, with surface temperatures upward of 735 Kelvin (K), well beyond what is necessary to melt most electronics and metals, with a weather system based on the movement of sulfuric acid.

Modes of robotic exploration of Venus have varied to deal with the intense environments of the Venusian atmosphere. During the Cold War of the mid-twentieth century, the United States of America tended to focus on Martian exploration, while the Russians focused on Venus. The Venera missions pursued exploration of Venus through orbiter missions, small scale balloons, drop probes and landers. The lander vehicle of Venera 13 was by far the longest lived surface explorer, surviving on the surface for 157 minutes before succumbing to heat and pressure. Both superpowers of the Cold War even planned manned Venus flybys using their technologies slightly re-adapted from the Moon Race. More recently, explorations have been spearheaded by the National Aeronautics and Space Administration (NASA), though mainly confined to fly-bys, the Japanese Aerospace Exploration Agency (JAXA), focusing on an orbiter mission, and the European Space Agency (ESA). Besides the numerous probes sent to orbit the planet, there has been less than a week of total surface and atmospheric exploration of the whole planet. Exploration above 50 kilometers, below which the haze layer starts to increase the acid content and reduce the amount of light available for photovoltaics, is appealing to both mission designers and planetary scientists. Geoffrey A. Landis of NASA's Glenn Research Center [1] and the Venus Exploration Analysis Group (VEXAG) [2] both call for exploration, habitation and potential colonization of Venus above the haze layer, where breathable air (20\% oxygen, $70 \%$ nitrogen) is a lifting gas and the atmosphere is Earth-like in quality.

Venus' climatological and geographical features are very intriguing to planetary scientists and others. The runaway greenhouse effect within the atmosphere of Venus could lend some insight into the future of our own planet, and the varied geography and acid based meteorology gives us insight into Venus's history. Additionally, in terms of human exploration, efficient transfer to Venus is easier than that to Mars, with mission opportunity windows being open every year and a half for Venus rather than every two years to Mars. Also, an exploration of potential round trip trajectories for Venus have been found to be as short as 14 months, compared to 26 months or more for Mars.

The High Altitude Venus Operational Concept (HAVOC) [3] focuses on the development of five potential phases of Venusian exploration and eventual habitation. Phase I focuses on robotic exploration, Phases II, III and IV focus on human study and exploration from orbit and then by airship, leading eventually to Phase $\mathrm{V}$ which focuses on longterm atmospheric habitation and colonization (See Figure 1). To develop the mechanisms of Phase III of this exploration, which involves a 30-day manned mission to the Venusian atmosphere, and improve its Technology Readiness Level (TRL), this project pursued two goals: 1) to construct a model that can demonstrate an Entry, Descent and Inflation (EDI) concept for an airship into the Venusian atmosphere and 2) to test different transparent films that can be used as solar cell protection against the atmosphere's harsh conditions.

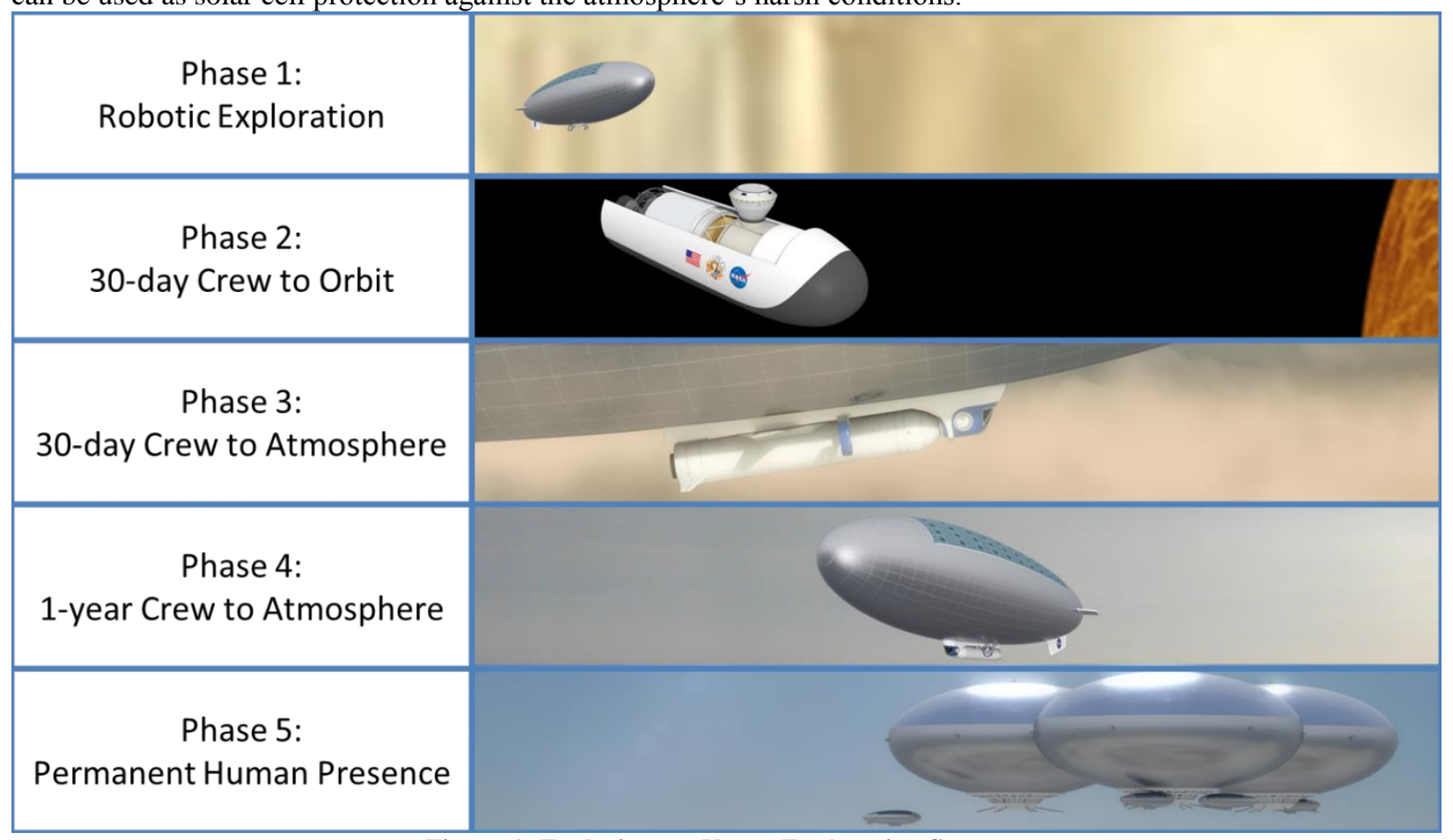

Figure 1: Evolutionary Venus Exploration Strategy 


\section{Model Airship Demonstration}

One of the challenges that comes with sending an airship to Venus is the process of visualizing the EDI and deployment of the entire vehicle into the atmosphere. Fully deployed, the airship is about the length of a Saturn V rocket, and three times as wide. For transfer using near-term technologies, that system must fit within a launch shroud of a similar size to the Saturn V's second stage [3]. By fabricating a physical model to demonstrate its EDI, the feasibility of the overall HAVOC Phase III mission can be better understood (see Figure 2). Thus, the team chose to build a model of the airship that included scale proxies of all the necessary components of the airship for a 30-day mission to the $50 \mathrm{~km}$ altitude in Venus's atmosphere, including the habitable gondola, the ascent vehicle (AV) and the inflatable structure. Ultimately, the model was designed to demonstrate the folding and packaging of all these components of the airship into a heat-shielding aeroshell, the EDI sequence the airship undergoes as it descends to 50 $\mathrm{km}$ and finally, the operation of the various electronic components on the gondola and ascent vehicle.

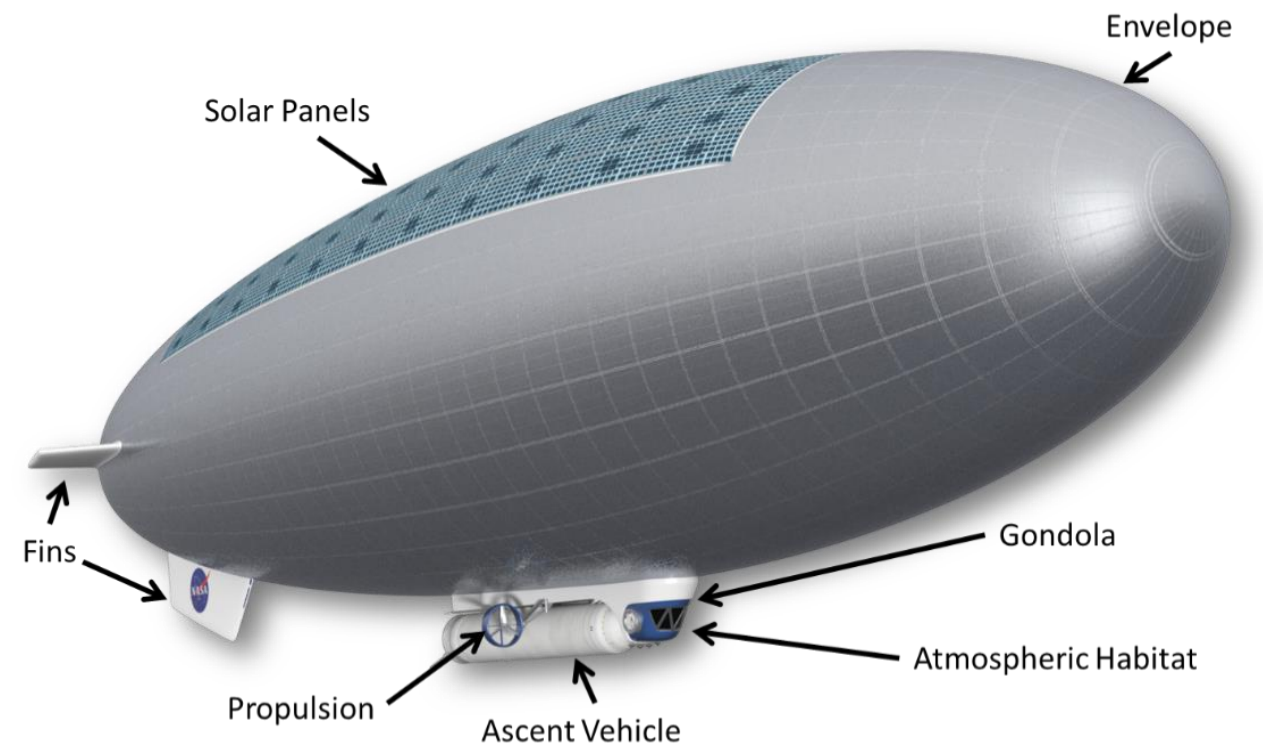

Figure 2: Vehicle concept for HAVOC Phase III mission.

Before building the physical model, the team began the proof of concept by developing an EDI sequence for the airship Certain constraints restricted design choices, such as g-force loading, complexity of unfolding design and the positioning of the inflatable structure. The Kepner-Tregoe Decision Making Process [4] was largely used to help the team organize different ideas for the folding, unfolding and inflation of the airship, as well as the process of releasing the various components of the aeroshell as the airship descended.

A key element of this study focused on the design, modeling, simulation, and analysis of two segments of the HAVOC trajectories: aerocapture and EDI [3,5]. During aerocapture the vehicle takes advantage of the drag created by flying through the atmosphere to reduce the speed of the vehicle, without the use of a large propulsive maneuver. Bank angle modulation is used to adjust the lift vector and guide the vehicle toward the desired target apoapsis, using a small propulsive burn to clean up any targeting errors. Once the vehicle is in the desired circular orbit, atmospheric entry may begin. During Entry, the entry vehicle (EV) is guided through the middle and lower atmosphere and may be maneuvered to prevent excessive heating and aerodynamic loads. Once the EV has slowed to supersonic velocities, the Descent phase begins when an aerodynamic decelerator, such as a parachute or ballute, is deployed to further reduce descent rate. The Inflation phase begins when the EV velocity is sufficiently reduced such that the airship may be exposed to the oncoming flow. The airship is pressurized during parachute descent and reaches a nominal altitude of approximately $50 \mathrm{~km}$.

Once the EDI sequence was developed (see Figure 3: HAVOC aerocapture, entry, descent, and inflation concept of operations. Notable events, with altitude, velocity, and time data, are given.Figure 3), the necessary materials to build a first physical scale-model were gathered to see if all the required components of the airship could fit into the aeroshell. An initial, simple physical model was constructed using nylon and cardboard measured to scaled dimensions, and showed that those elements would fit into a scaled-aeroshell. Afterward, the team began designing the final model of the airship using a variety of methods, including 3D-modelling, sewing, electronic system design and pneumatic system design. The most important requirements considered when designing the final model were 1)

American Institute of Aeronautics and Astronautics 
to keep everything to-scale to show that everything would, in fact, fit inside the aeroshell feasibly; and 2) to design according to the EDI sequence.

Certain parts of the airship needed to have solid structure, such as the aeroshell, gondola, ascent vehicle, helium tanks, fins, and nose cones, and thus were designed using 3D-modelling, then 3D-printed using ABS plastic. Other parts, such as the inflatable structure, needed to be flexible and easy to fold around the hard components of the airship. To show the movement of the ascent vehicle and the deployment of the inflatable structure, electronics and pneumatic systems were designed and integrated into the model. These systems were designed using commercial off-the-shelf components, including an Arduino Uno microcontroller, a gas bag derived from an advertising blimp, and pneumatic tubing. Components like the airship envelope, which was sewn together based off of plans developed by the team and the onboard breakout shield for the gondola's electronics, were custom made.

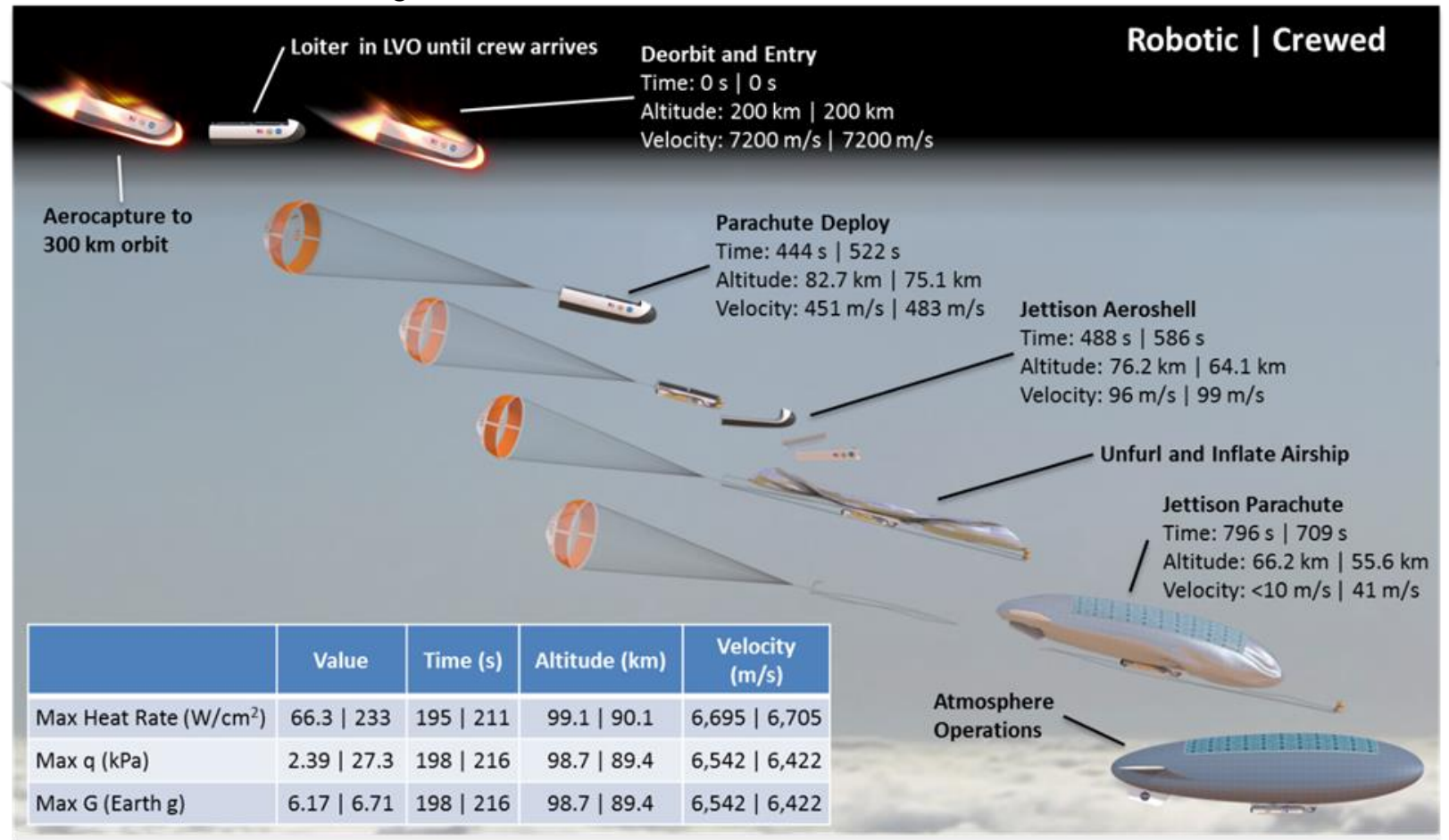

Figure 3: HAVOC aerocapture, entry, descent, and inflation concept of operations. Notable events, with altitude, velocity, and time data, are given.

The final airship proof of concept model was developed at a $1 / 53 \mathrm{rd}$ scale $(0.75$ inches/meter, although the thicknesses of the envelope and payloads was not correspondingly modified due to material limitations. The folding algorithm used to package the airship envelop is shown in Figure 4 through Figure 8. This folding algorithm has heritage in the folding techniques of the parachutes deployed from model rockets[6],allowing it to unfold rapidly without binding. Compression straps were used to further tighten and compress the balloon payload so all components could fit within the entry aeroshell. 


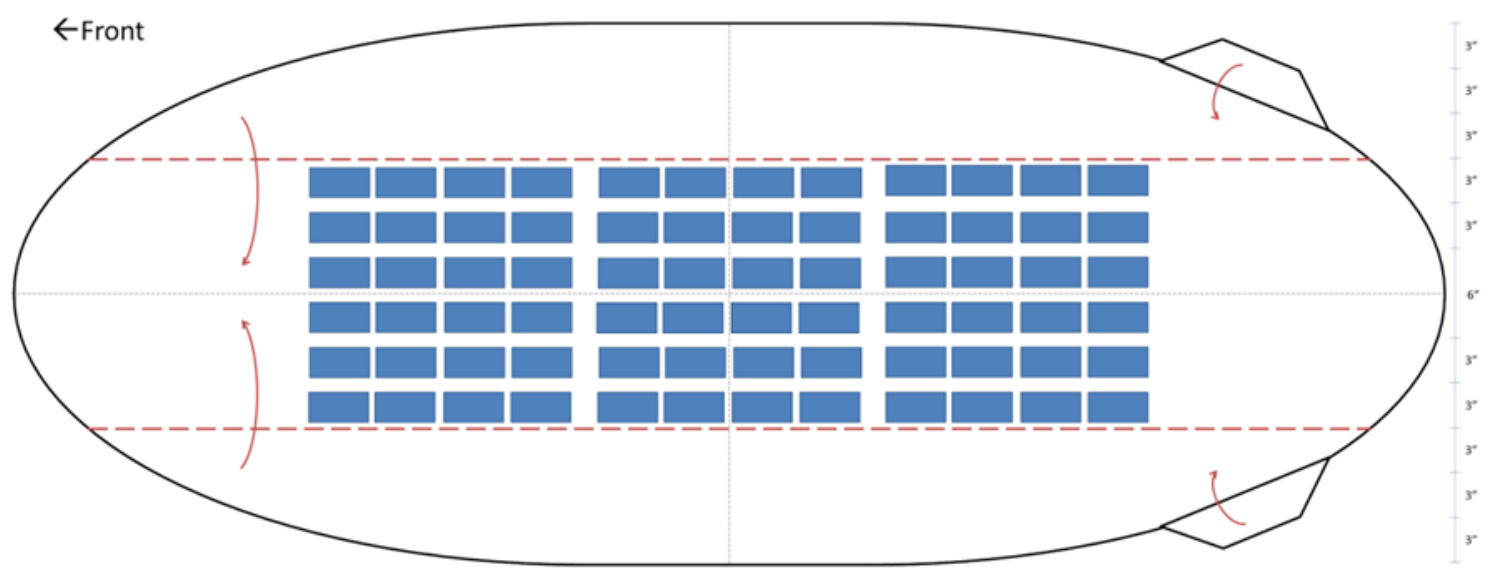

Figure 4: First step of folding airship envelope for packaging demonstration. The airship envelope is flattened and, and the lateral sides are folded into the middle.

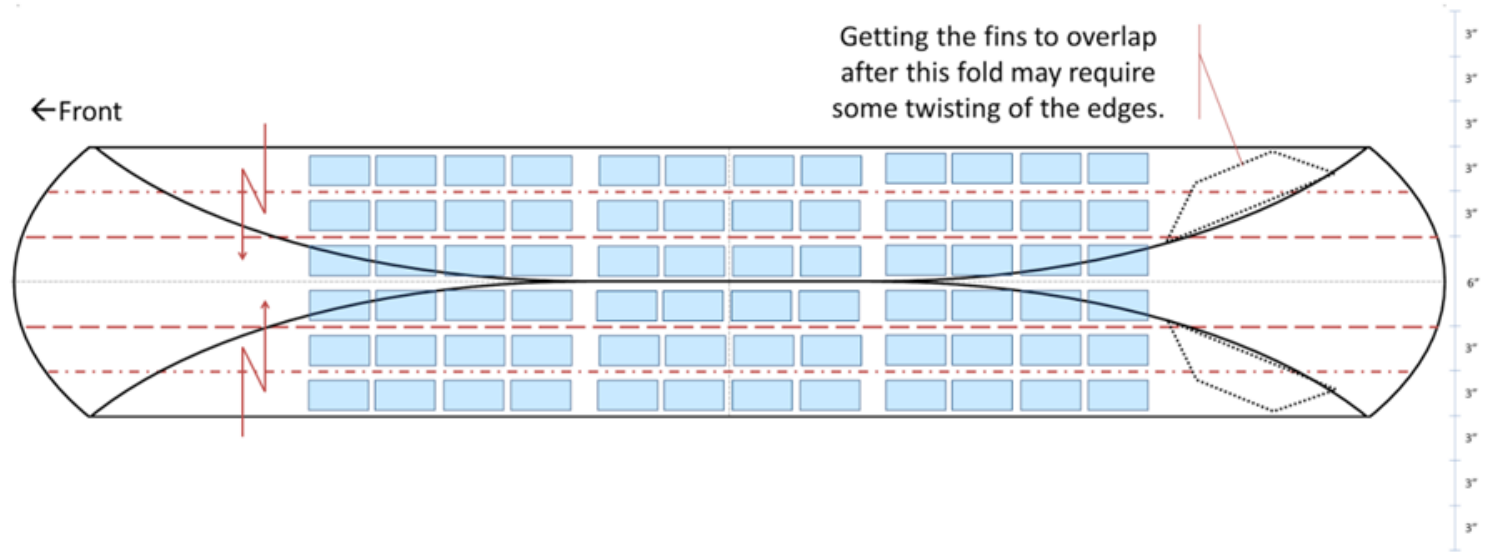

Figure 5: Second step of folding airship envelope for packaging demonstration. Each side is "Z-folded" into the middle, with the folds occurring between the rows of solar panels. The fins are made to overlap.

$\leftarrow$ Front

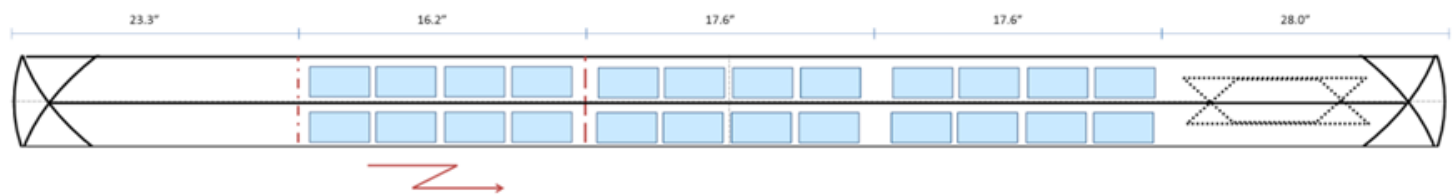

Figure 6: Third step of folding airship envelope for packaging demonstration. Velcro straps are used to cinch the four outer segments of the airship envelope (at approximately the locations of the dimensions on the figure above), while the middle segment is left unbound. The front end is then Z-folded so that it lays over the middle segment.

American Institute of Aeronautics and Astronautics 


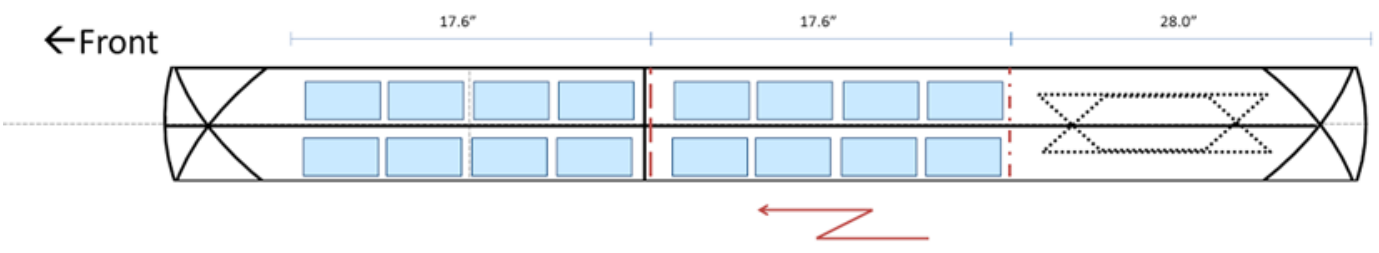

Figure 7: Fourth step of folding airship envelope for packaging demonstration. The back end is Z-folded over the middle segment, as previously done with the front end.

\section{$\leftarrow$ Front}

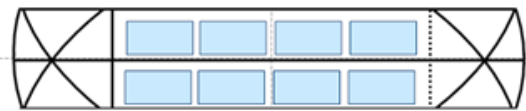

Figure 8: Fifth step of folding airship envelope for packaging demonstration. The folded bundle is attached to the gondola, then another Velcro strap is used to cinch the middle segment to expel any remaining air in the envelope.

From this starting configuration within the aeroshell, the top is removed, and then the sides fall away, exposing a majority of the folded gas envelope. Then, the folds are undone by tugging on the front simulated TPS sled and the back deceleration plate (where the supersonic decelerator would be attached). This action brings the airship to its total length and the compression straps are removed. The airship is inflated using an external pump and hose connected to the gas bag. Inflation typically happens within a minute. The inflated airship with gondola is shown in Figure 9.

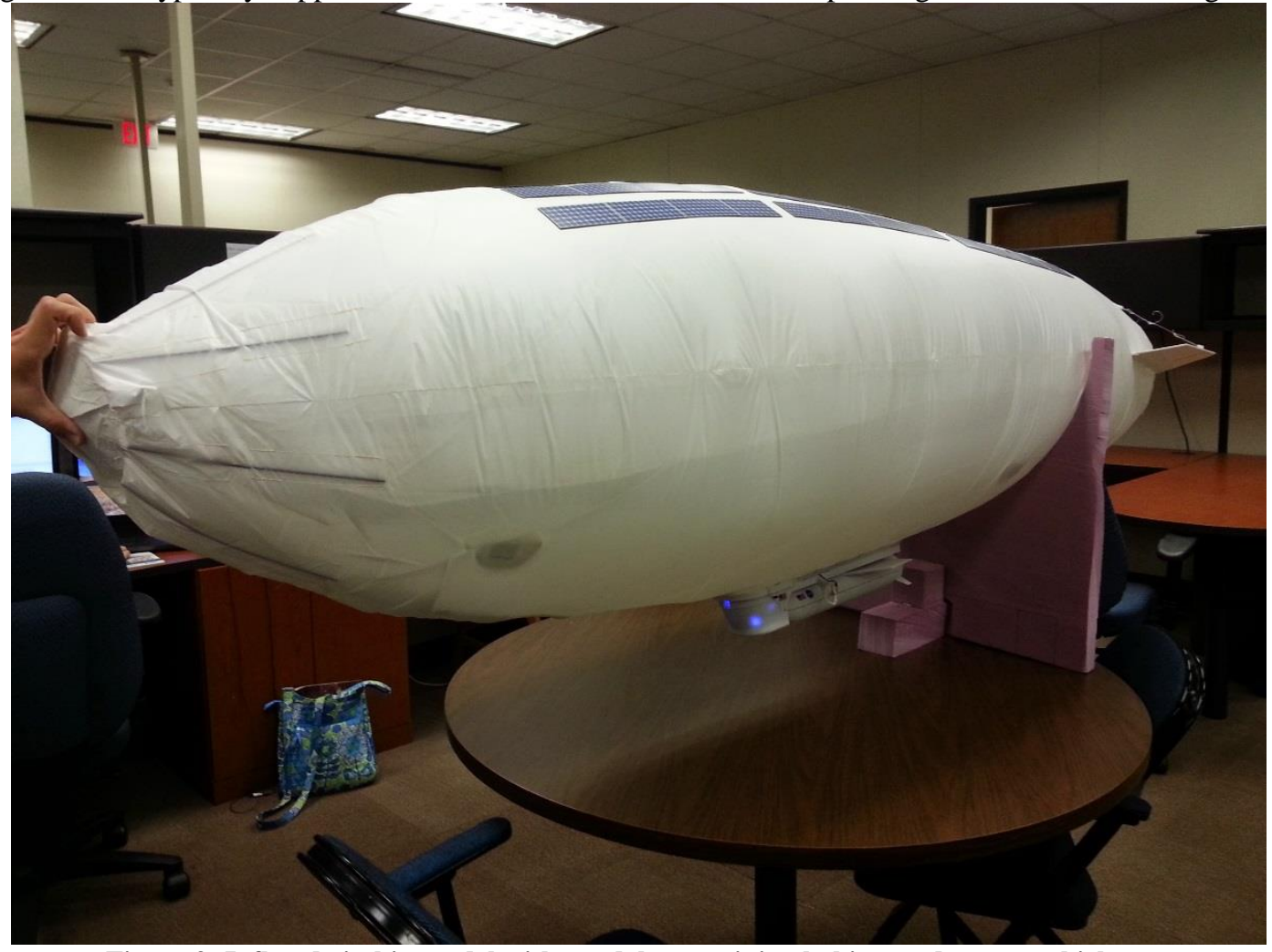

Figure 9: Inflated airship model with gondola containing habitat and ascent vehicle. 
Because the scaled airship fits within the scaled aeroshell (despite the disproportionately scaled thickness of the gasbag and gondola elements), this model indicates that the Phase III airship can be packaged within the 10 meter by 30 meter aeroshell of an SLS Block 2B vehicle.

\section{Sulfuric Acid Resistant Material Testing}

The airship will be powered by solar cells that lay along the top surface of the inflatable structure. While the atmosphere at the operating altitude of $50 \mathrm{~km}$ is favorable for human exploration relative to the surface of Venus, there are droplets of highly concentrated sulfuric acid floating in the local atmosphere. This sulfuric acid could potentially degrade the surface of the solar cells, which would inhibit energy production for the airship. It is important to find some transparent coating that can protect the surface of the solar cells against the sulfuric acid during the 30day operation in the atmosphere, while still permitting the useful wavelengths for the solar cells to pass through. Thus, the team designed an experiment to test the physical integrity and optical clarity of several films after being submerged in a sulfuric acid solution ranging in concentrations from $75 \%$ to $85 \%$ for a 30 -day period.

Given these criteria, polyvinyl chloride (PVC), polypropylene (PP), and fluorinated ethylene propylene (FEPTeflon) were identified as candidate materials for testing. From a review of chemical resistances [7],the team expected that FEP would likely not be affected by sulfuric acid, PP would be affected minutely, although it should be noted that its performance was only rated up to $49^{\circ} \mathrm{C}$, and PVC would be affected minutely as well, despite having performance rated up to $22{ }^{\circ} \mathrm{C}$ (all data based on $98 \%$ sulfuric acid solution). These three different materials were soaked in both $75 \%$ and $85 \%$ concentrated sulfuric acid for 1,7 , and 30 days to ensure that the materials were resistant in the range of sulfuric acid that is found on Venus at the $50 \mathrm{~km}$ altitude and can last for the expected length of the mission. This resulted in the team preparing 18 samples.

To measure the impact of sulfuric acid immersion on these materials, the team prepared test samples in the shape shown in Figure 10. The team cut the samples into rectangular strips, which were then folded over and sealed with a heat sealer (the hashed areas in the figure). The middle area was thus an enclosed pocket that would ensure that only one side of the material was exposed to acid. The open area at the top of the sample allowed for a dowel to be inserted so that the sample could be suspended in a beaker of acid. After the team removed the sample from the acid, the sample was rinsed and dried. The team cut a 1 inch by 1 inch square section from the middle area, which was then tested for physical and optical properties.

The team used Fourier Transform Infrared spectroscopy (FT-IR) and Ultraviolet-visible-near-infrared (UV-VISNIR) spectroscopy to assess the spectral properties of the samples after acid immersion, as well as control samples that were not exposed to acid. The FT-IR machine collected spectral data that was used to determine if there were any chemical changes in the material over time. The UV/VIS/NIR spectrometer measured the amount of transmittance for a material from the ultraviolet to infrared spectrum $(100-1000 \mathrm{~nm})$. The team used this data to evaluate the degradation in transmittance after exposure to sulfuric acid. The team used a scale, micrometer, and a ruler to measure weight and linear dimensions of the samples to see if there were any changes in physical properties of the samples.

Table 1 shows the results of the UV-VIS-NIR spectroscopy for each of the six samples (FEP, PP, and PVC at 75\% and $85 \%$ concentrations) after $0,1,7$, and 30 days. The value is the averaged transmittance over the $300 \mathrm{~nm}$ to 1000 $\mathrm{nm}$ wavelengths; this is used as a metric for the capacity of the material to transmit visible light to the solar panels. The FEP and PP samples saw negligible decay (within the $2 \%$ accuracy of the spectroscopy) in transmittance over 30 days. The PVC sample in 75\% concentration began to turn brown an hour after immersion, and saw a sharp decline in transmittance after a single day, with small further declines measured in the 7-day and 30-day samples. When extracted and cleaned after immersion, the PVC sample in $85 \%$ concentration produced a persistent "sweat" even after being baked in a $70{ }^{\circ} \mathrm{C}$ vacuum oven for over four hours, and the team found sulfuric acid inside the middle pocket of the sample. when they were cut open in preparation for spectral analysis, some sulfuric acid was found inside. At first, the team suspected that the 1-day sample might have been fabricated with a leak, but the 7-day sample also contained internal acid, and appeared to have corroded the neighboring sample slightly while they were drying in the oven. Because the intent of the test was to keep the pockets sealed and only expose the outer surface to acid, and because the residual acid might damage the testing equipment, the $85 \%$ PVC samples were discarded and not measured in either spectroscope. Figure 11 through Figure 15 show the transmittance versus wavelength for each material and concentration, across the 0-day, 1-day, 7-day, and 30-day samples.

American Institute of Aeronautics and Astronautics 


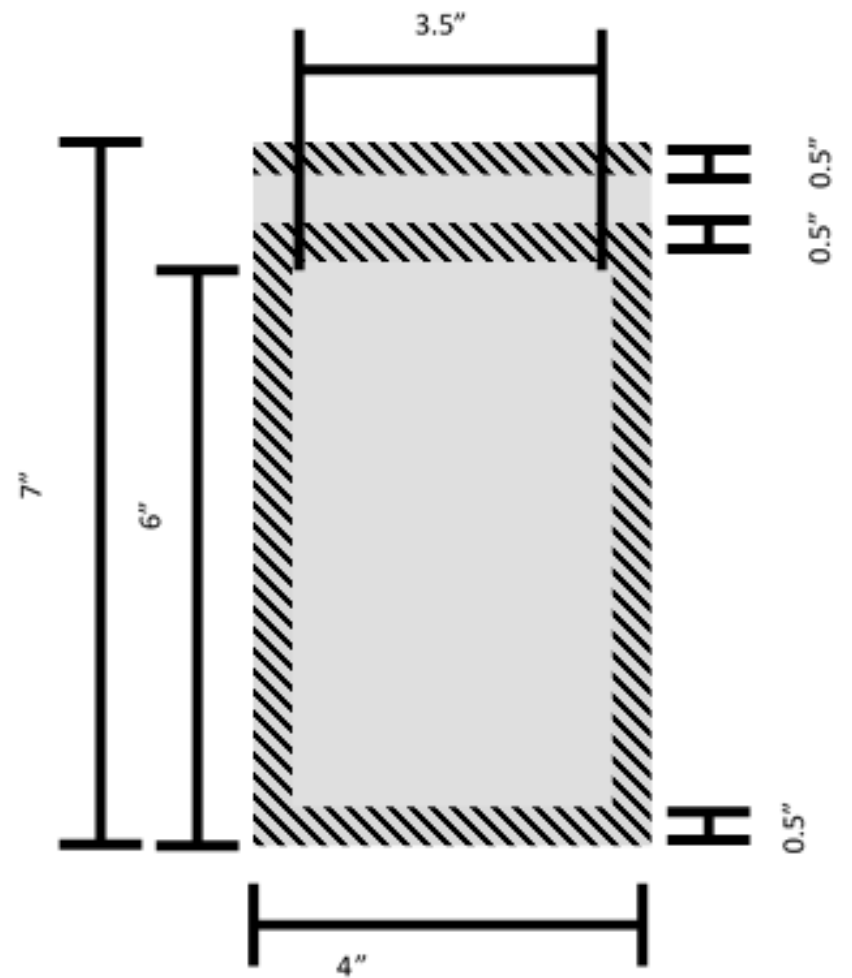

Figure 10: Test sample dimensions. The hashed areas were sealed using a heat press.

Table 1: Average Transmittance over $300 \mathrm{~nm}$ to $1000 \mathrm{~nm}$.

\begin{tabular}{|l|c|c|c|c|}
\hline $\begin{array}{c}\text { Material \& } \\
\text { Concentration }\end{array}$ & Unexposed & $\mathbf{1}$ day & $\mathbf{7}$ days & $\mathbf{3 0}$ days \\
\hline FEP 75\% & $91.5 \%$ & $93.1 \%$ & $90.3 \%$ & $92.6 \%$ \\
\hline FEP 85\% & $91.5 \%$ & $92.9 \%$ & $92.9 \%$ & $93.2 \%$ \\
\hline PP 75\% & $90.7 \%$ & $90.6 \%$ & $90.1 \%$ & $90.5 \%$ \\
\hline PP 85\% & $90.7 \%$ & $91.1 \%$ & $90.9 \%$ & $91.1 \%$ \\
\hline PVC 75\% & $80.2 \%$ & $47.6 \%$ & $45.7 \%$ & $42.6 \%$ \\
\hline PVC 85\% & $80.2 \%$ & N/A & N/A & N/A \\
\hline
\end{tabular}




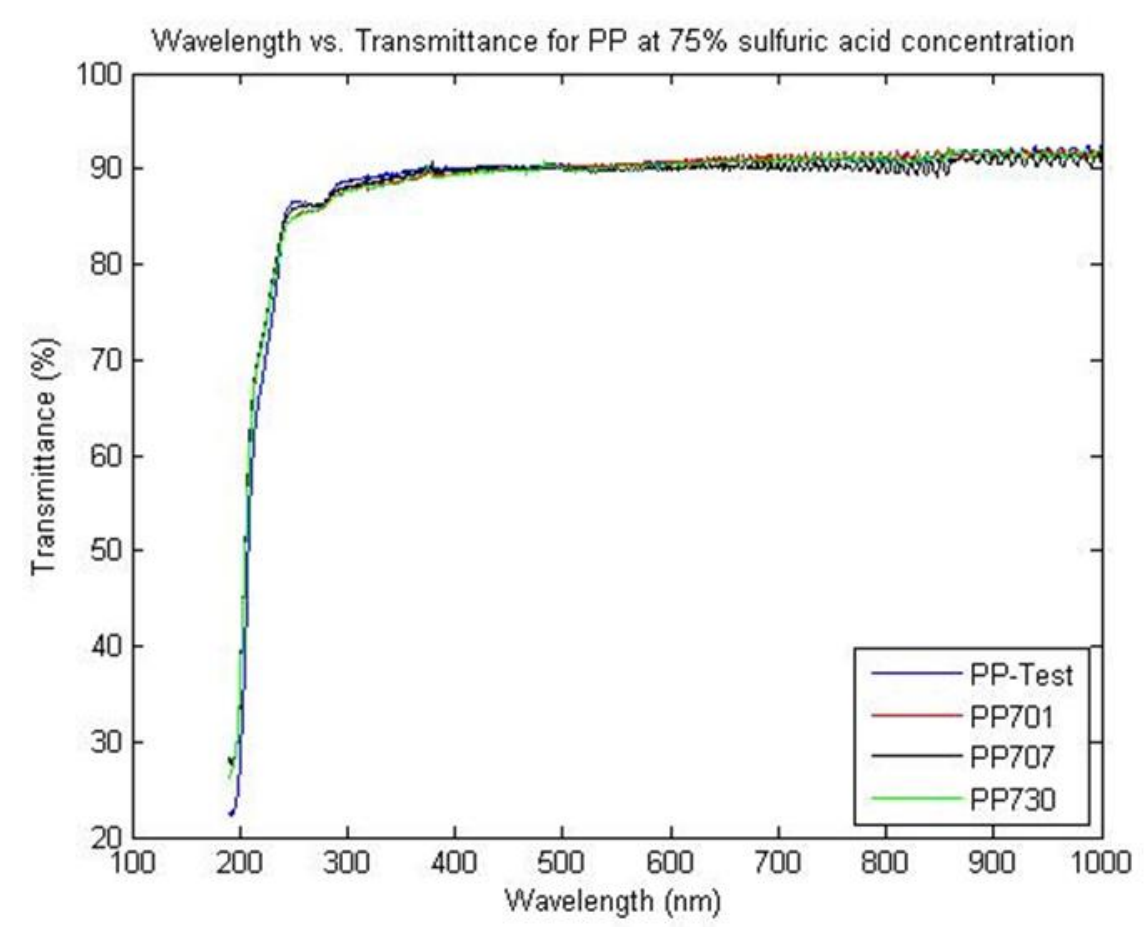

Figure 11: Transmittance as a function of wavelength for polypropylene in $\mathbf{7 5} \%$ concentration sulfuric acid solution.

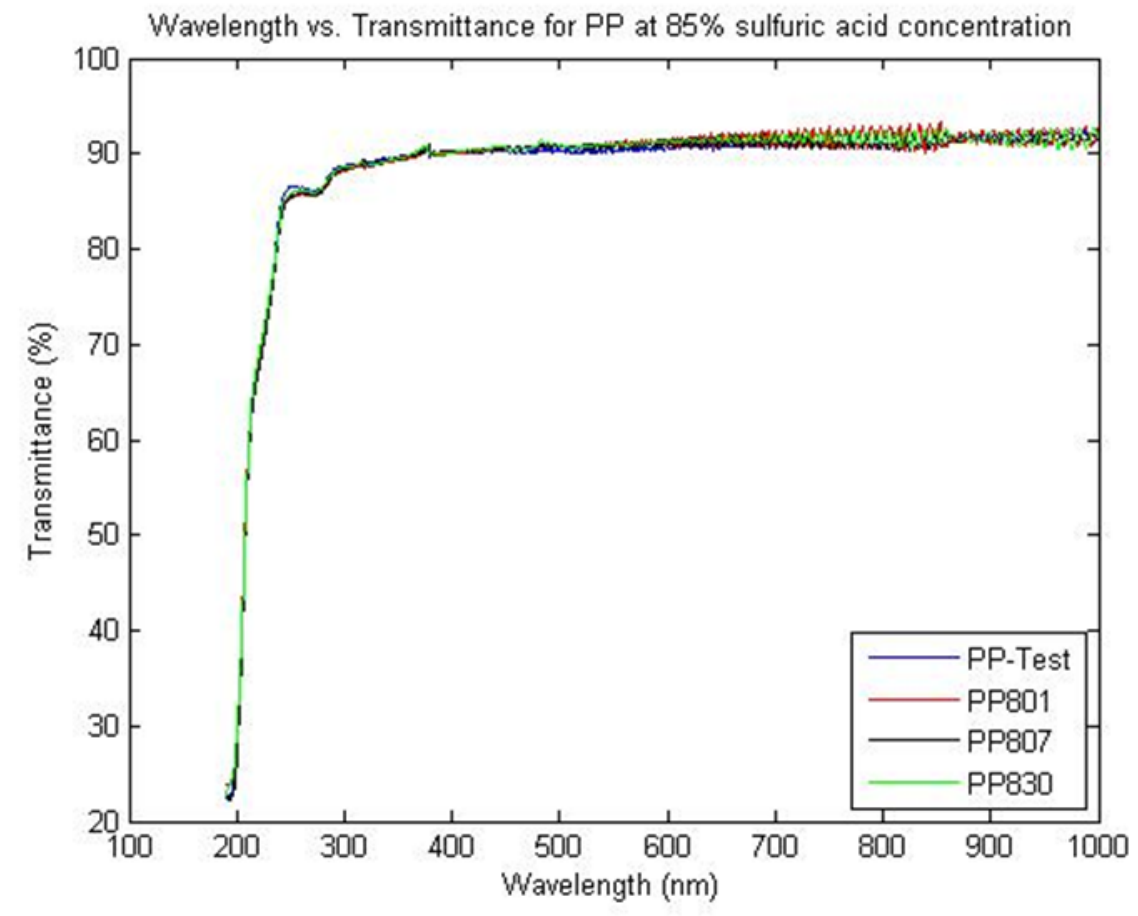

Figure 12: Transmittance as a function of wavelength for polypropylene in $85 \%$ concentration sulfuric acid solution.

American Institute of Aeronautics and Astronautics 


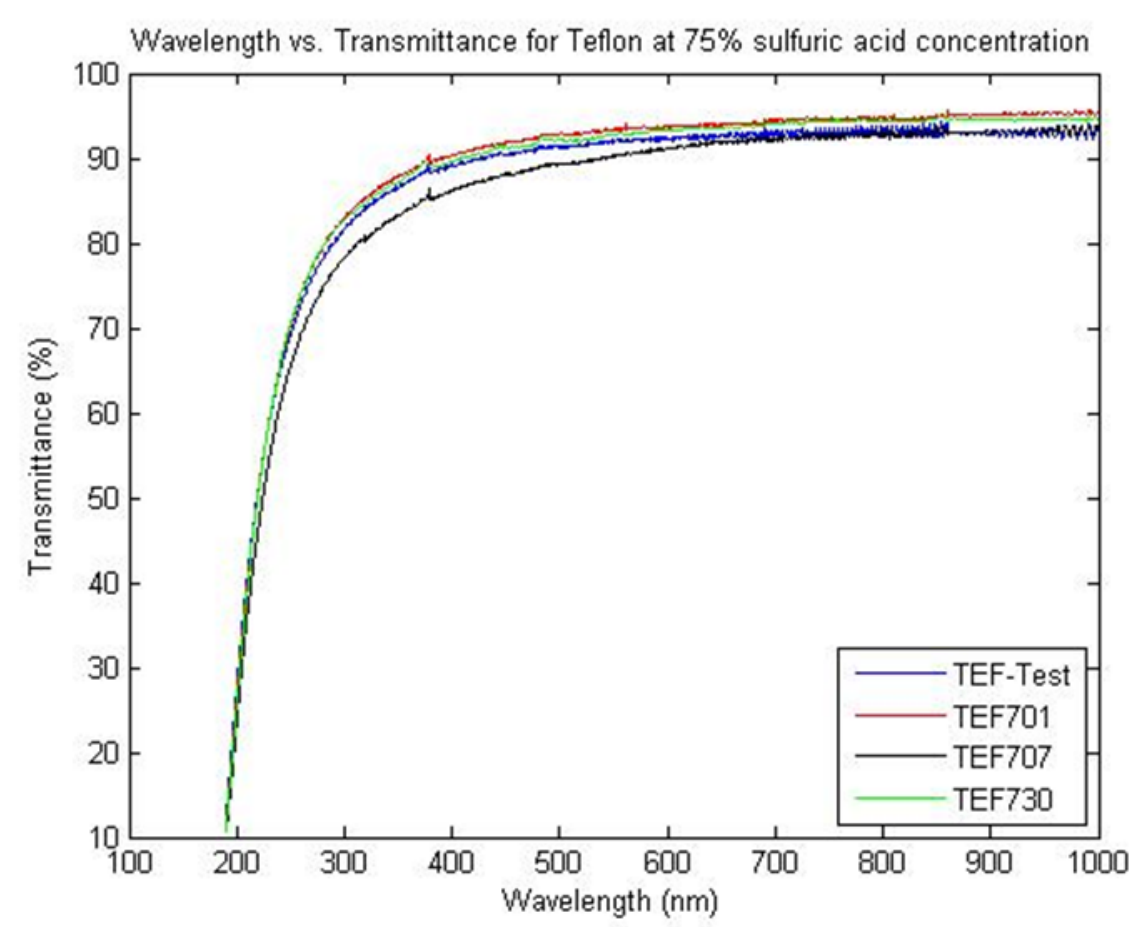

Figure 13: Transmittance as a function of wavelength for FEP-teflon in $75 \%$ concentration sulfuric acid solution.

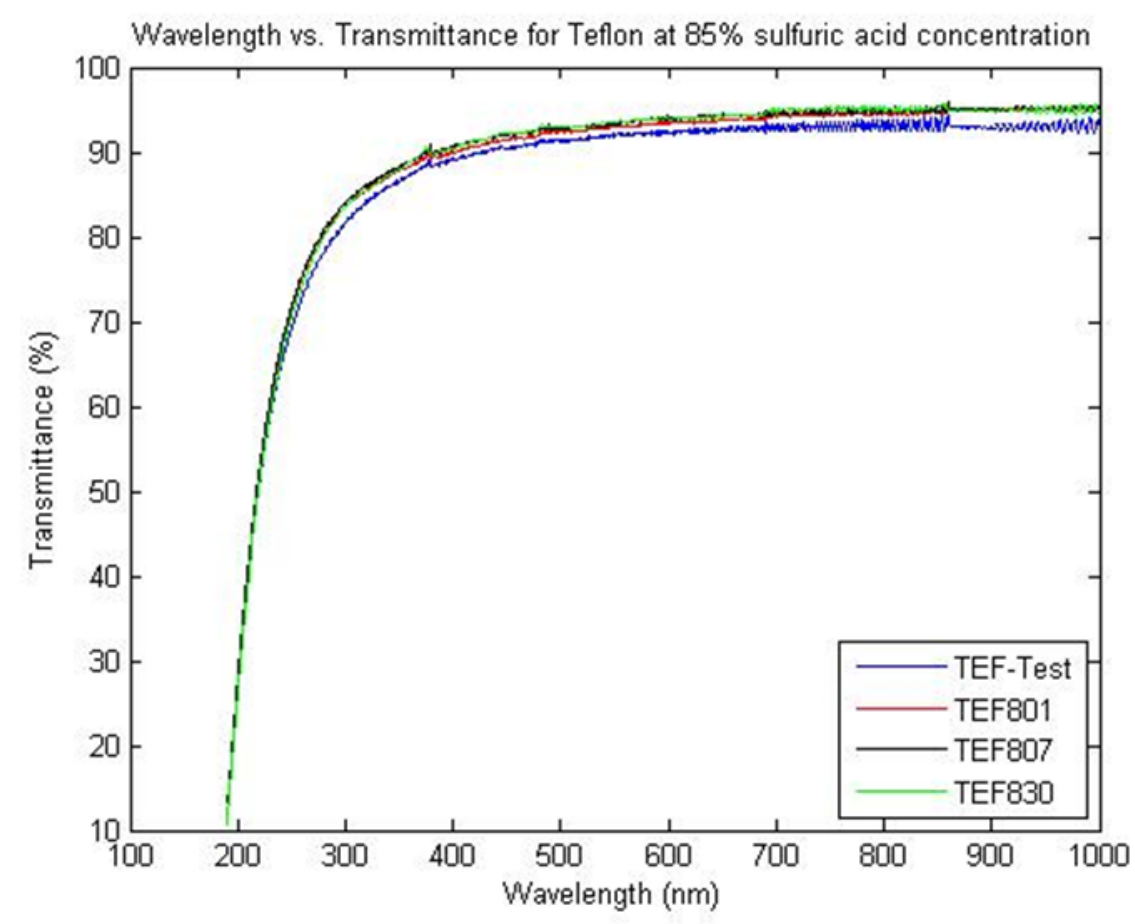

Figure 14: Transmittance as a function of wavelength for FEP-teflon in $85 \%$ concentration sulfuric acid solution.

From analysis of the FT-IR data, only PVC underwent a chemical change. Figure 16 shows the transmittance versus wavenumber for the PVC sample in 75\% concentration at each time step. The spike occurring at 3000-3500 $\mathrm{cm}^{-1}$ indicates that the reaction that took place could have created a low concentration carboxylic acid, based on a review of group absorption frequencies in infrared spectroscopy [8]. An indicator of carboxylic acids is that they have strong odors that have volatile derivatives; some examples are acetic acid (vinegar) and butyric acid (human vomit)

American Institute of Aeronautics and Astronautics 
[9]. When the PVC sample was pulled out of the sulfuric acid, a distinct odor came from the material that is comparable to acetic acid and butyric acid, It should be noted that this is an untested hypothesis based off of the data that was collected in this experiment

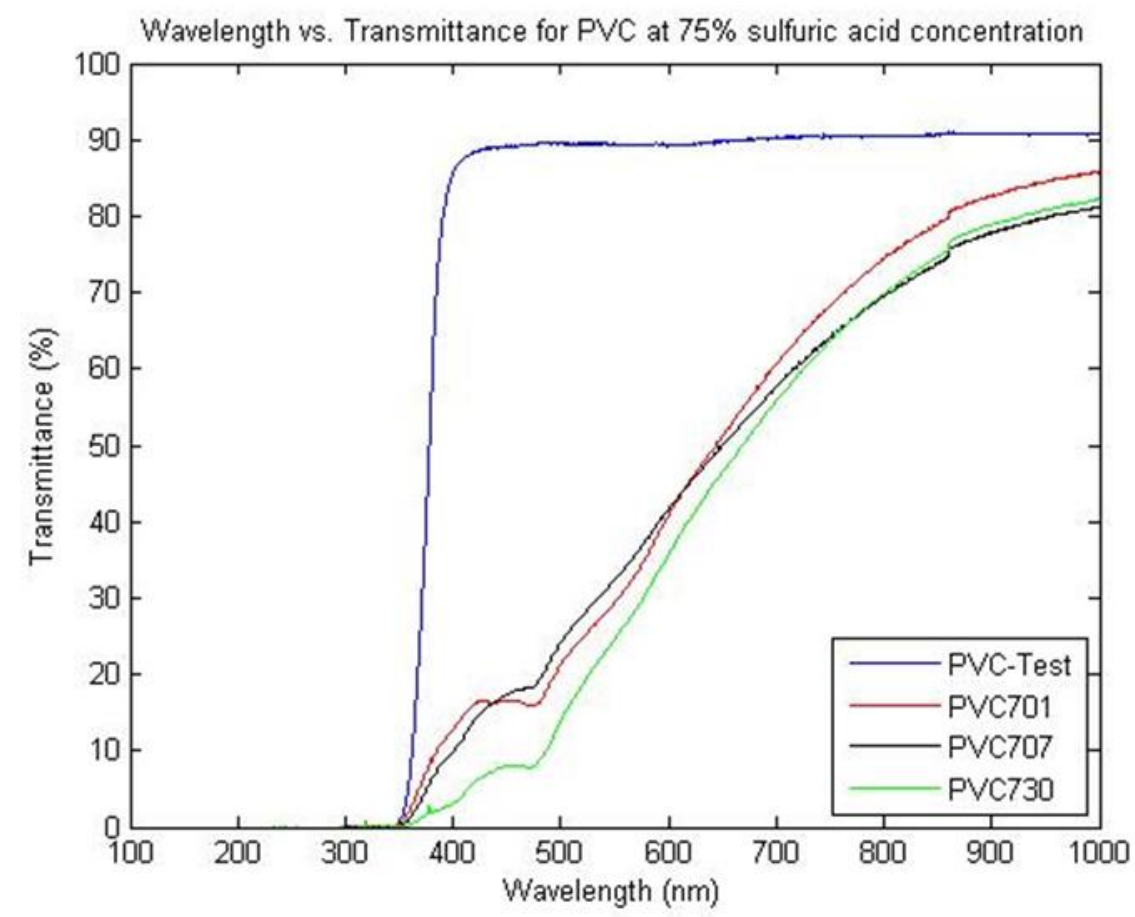

Figure 15: Transmittance as a function of wavelength for polyvinyl chloride in $75 \%$ concentration sulfuric acid solution.

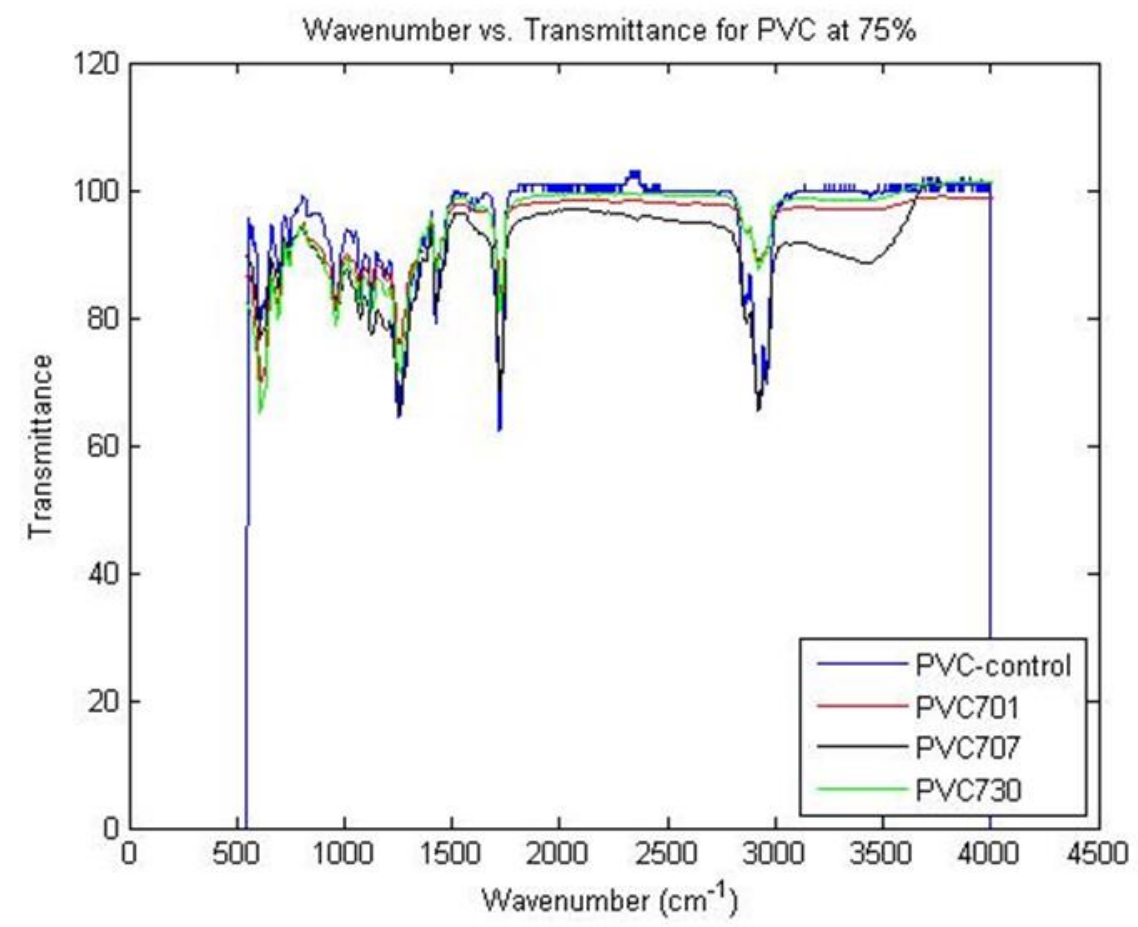

Figure 16: Transmittance vs wavenumber for polyvinyl chloride in $\mathbf{7 5 \%}$ concentration sulfuric acid solution. The shift in the curves over time (from blue, through red and black, to green) indicates a chemical composition change.

American Institute of Aeronautics and Astronautics 


\section{Conclusion}

The HAVOC study has developed an evolutionary exploration plan for Venus that can meet scientific objectives for planetary science while offering another destination for human exploration beyond Earth. Two proof of concept demonstrations have indicated feasibility for the proposed airship concept. The team showed that a scale model of an airship can be packaged within a scale model of an aeroshell. The team also found the FEP-teflon shows promise as a material for protecting solar panels and other elements of the airship from the ambient sulfuric acid. Future analysis would include understanding how to attach the FEP-teflon to the solar panels, and testing the integrated performance in an accurate environment. Ultimately, the authors conclude that Venus, with its relatively hospitable upper atmosphere, can play a role in humanity's future in space.

\section{Acknowledgments}

The authors would like to thank the Systems Analysis and Concepts Directorate at NASA Langley Research Center for funding this study. Additionally, the authors would like to thank Mia Siochi, Godfrey Sauti, Yi Lin, James Lana, and David North for their facilities and assistance in conducting these proofs of concept.

\section{References}

1. Landis, G. "Colonization of Venus.” Conference on Human Space Exploration, Space Technology \& Applications International Forum, Albuquerque NM, Feb. 2-6 2003.

2. Herrick, R., Baines, K., Bullock, M., Chin, G., Grimm, B., Kiefer, W., Mackwell, S., McGouldrick, K., Sharpton, B., Smrekar, S., Tsang, C. "Goals, Objectives, and Investigations for Venus Exploration: 2014.” Venus Exploration Analysis Group. 2014.

3. Arney, D., Jones, C., "High Altitude Venus Operational Concept (HAVOC): An Exploration Strategy for Venus," AIAA SPACE 2015 Conference and Exposition, Pending Publication, 2015.

4. Scheubrein, R., Zionts, S. "A Problem Structuring Front End for a Multiple Criteria Decision Support System," Computers and Operations Research, Vol. 33, No. 1, pp 18-31, January 2006.

5. Lugo, R., Ozoroski, T., Van Norman, J., Arney, D., Dec, J., Jones, C., Zumwalt, C. "High Altitude Venus Operations Concept Trajectory Design, Modeling, and Simulation." $25^{\text {th }}$ AAS/AIAA Space Flight Mechanics Meeting. AAS15223. 2015.

6. Stine, G., Stine B., Handbook of Model Rocketry, $7^{\text {th }}$ edition, Hoboken, NJ: Wiley, 2004.

7. Pumprite Inc., "Chemical Resistance Chart," http://www.pumprite.com/chemre.pdf, Accessed 7-24-15.

8. Reusch, W., "Infrared Spectroscopy," http://www2.chemistry.msu.edu/faculty/reusch/virttxtjml/spectrpy/InfraRed/infrared.htm, Accessed 7-27-15.

9. BBC, "Carboxylic Acid and Esters," http://www.bbc.co.uk/schools/gcsebitesize/science/triple_ocr_21c/further_chemistry/carboxylic_acids_esters/revision/1 l, Accessed 7-27-15. 